\title{
Pleural Effusion and Plasma Levels of Fibrinolytic Parameters in Tuberculosis Pleurisy and Contribution to the Diagnosis
}

\author{
Burcu Akkök ${ }^{1}$, Sibel Yurt ${ }^{1}$, Burcu Arpınar Yiğitbaş ${ }^{1}$, Hafize Uzun², Filiz Koşar $^{1}$ \\ ${ }^{1}$ Department of Chest Diseases, Yedikule Chest Diseases and Chest Surgery Education and Research Hospital, İstanbul, Turkey \\ ${ }^{2}$ Department of Medical Biochemistry, İstanbul University, Cerrahpaşa Medical Faculty, İstanbul, Turkey
}

\begin{abstract}
Objective: The presence of a relationship between tuberculosis and hypercoagulability has been reported. In the case of the occurrence of hypercoagulability, the body responds by activating the fibrinolytic system. In this study, we aimed to investigate the values of fibrinolytic parameters and their contribution to the diagnosis in patients with tuberculosis pleurisy (TP).

Methods: Forty four patients with tuberculosis pleurisy (30 cases), malignant plural effusion ( 8 cases), and transudative pleural effusion (6 cases) were involved in the study. Transudative and malignant fluids constituted the control group. The concentrations of pleural fluid and plasma D-Dimer, fibrinogen, tissue plasminogen activator (t-PA), plasminogen activator inhibitor 1 (PAI-1), t-PA/PAI-1 complexes and serum, and pleural fluid, adenosine deaminase (ADA), glucose, lactate hydrogenase (LDH), total protein and albumin levels of the cases were measured.

Results: In the patients with tuberculosis pleurisy, the values of pleural fluid fibrinogen and pleural fluid PAI-l were found to be significantly higher according to the results of Mann-Whitney $U$ test ( $p \leq 0.05$ and $p \leq 0.001$, respectively).

Conclusion: In tuberculosis pleurisy, fibrinolytic system activates in parallel with the increased hypercoagulation and fibrinolytic parameters also increase. These parameters can be benefited unless the diagnosis of tuberculosis pleurisy can be established through conventional diagnostic methods.
\end{abstract}

Keywords: D-Dimer, fibrinogen, PAI-1, tuberculosis pleurisy

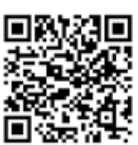

Received Date: 02.08 .2013 Accepted Date: 23.02.2014

Address for correspondence

Burcu Akkök, Yedikule Göğüs Hastalıkları ve Göğüs Cerrahisi Eğitim ve Araştırma Hastanesi, İstanbul, Turkey

E-mail: bkaraokur@hotmail.com

(C) Copyright 2014 Turkish Respiratory Society (TRS) Eurasian J Pulmonol 2014

DOI: $10.5152 /$ ejp.2014.15010

- Available online at www.eurasianjpulmonol.com

\section{INTRODUCTION}

Tuberculosis pleurisy (TP) is a form of extrapulmonary tuberculosis that is frequently encountered in our country. It generally occurs as lymphocyte-dominant exudate fluid. The diagnosis of tuberculosis pleurisy is made through the detection of tuberculosis basil in sputum, pleural fluid or pleural tissue sample or the histopathological demonstration of granuloma with necrosis in the pleural tissue. However, the gold standard for diagnosis is the production of mycobacterium tuberculosis in culture. In spite of this, culture positivity is present only in $15-20 \%$ of the cases (1-3). The diagnostic value of closed pleural biopsy in tuberculosis pleurisy ranges from $60 \%$ to $80 \%(4,5)$. However, $10-30 \%$ of the tuberculosis pleurisy cases cannot be diagnosed through conventional methods. In these situations, non-invasive, easily applicable and accessible tests are needed in countries like Turkey, where the frequency of tuberculosis is high. In the studies conducted to date, the use of some methods including IL-2, IL- 6 , IL-12, CD-8, adenosine deaminase (ADA), tuberculostearic acid, lysozyme, polymerase chain reaction (PCR) and interferon- $\gamma$ ( IFN- $\gamma$ ) in establishing diagnoses was investigated. Among these tests, the most prominent is ADA with high specificity and sensitivity. Adenosine deaminase is the most commonly used alternative diagnostic method today owing to its low-cost and the fact that it is easily accessible. Nonetheless, additional parameters are required because of the increase of ADA in many diseases (6). For this aim, many studies have been conducted regarding fibrinolytic system parameters in TP. The fibrinolytic system protects the body against excessive fibrin load and acts in balance with fibrinogenesis beyond coagulation. Its main activators are plasminogen activators. Plasminogen activator inhibitors interfere with the system. Some studies have reported a relationship between tuberculosis pleurisy and hypercoagulation. The tendency to hypercoagulation was correlated with proinflammatory cytokines. In the case of increased hypercoagulation, the body responds by activating the fibrinolytic system. 
This study was performed to investigate the values of fibrinolytic system parameters in pleural fluid and plasma, and their contribution to the diagnosis in patients with TP. All fibrinolytic parameters were examined and their correlation with TP was evaluated.

\section{METHODS}

This study was conducted in Yedikule Pulmonary Diseases and Thoracic Surgery Training and Research Hospital between May 2010 and July 2011. Forty four patients ( 14 female and 30 male) were included. At the beginning, the patients were informed about the study in detail and their written informed consent was obtained. The cases participating in the study were put into two groups: transudative and exudative pleural fluids (7). Exudative fluids were further categorised into two subgroups: tuberculosis and malignant pleural fluids. Transudative and malignant fluids constituted the control group.

In order to study D-Dimer, fibrinogen, tissue plasminogen activator (t-PA), plasminogen activator inhibitor 1(PAI-1), t-PA/PAI-1 and ADA, a $10 \mathrm{cc}$ pleural fluid sample was collected from the patients at the same time as blood samples were collected. After these samples were centrifuged at $3000 \mathrm{rpm}$ for 30 minutes, the supernatant was taken into Eppendorf tubes and stored at $-40^{\circ} \mathrm{C}$ until the study day. The blood samples were put into tubes containing 3.2\% citrate. These materials were studied in Cerrahpaşa Medical Faculty of Istanbul University. The value of ADA in pleural fluid sample was measured using a colorimetric method (Colorimetric DIAZYM ADA KIT 250 TEST CAT NO: DZ117A). Plasma and pleural fluid D-Dimer (HYPHEN Biomed, D-Dimer, Catalogue Number: RK023A), fibrinogen (Assaypro, USA, Catalogue No. EF1040-1), t-PA/PAI-1 complex (Assaypro, USA, Catalogue No. EP1105-1), PAI-1 (Assaypro, USA, Catalogue No.EP1100-1) and tPA (Assaypro, USA, Catalogue No. ET1001-1) were studied using commercial kits based on the principle of competitive ELISA.

Advanced invasive examination was not performed in transudative fluids, but closed pleural biopsy was carried out for patients with lymphocyte-dominant exudate fluid if no diagnosis was made through the use of other methods.

\section{Statistical Analyses}

Descriptive statistics of the data were demonstrated in the values of mean, standard deviation, frequency and percentage. Distribution of the data was evaluated with the Kolmogorov-Smirnov test. For the analysis of parametric data, the T-test was used. For the analysis of non-parametric data, the Mann-Whitney $U$ test was employed, while the analysis of percentages was performed using the Chi-square test. SPSS 19.0 for Windows was used for analyses.

\section{RESULTS}

Thirty TP cases and 14 non-tuberculosis pleural effusion cases (8 malignant pleural effusion and 6 transudative pleural effusion), who were within the age range of 20-97 years, were involved in the study.
The diagnosis of tuberculosis pleurisy was established by the presence of pleural fluid with parenchymal lesion in granulation tissue revealed by closed pleural biopsy in 29 of 30 patients and the presentation of tuberculosis basil in sputum in one patient. Seven of 8 patients with malignant pleural fluid were diagnosed through closed pleural biopsy and the other patient was diagnosed through the appearance of malignant cells in the pleural fluid. Of the cases with malignant pleural fluid, 1 patient was diagnosed with primary lung carcinoma, 3 patients with malignant masothelioma, 1 patient with lymphoma metastasis, and 3 patients with metastatic adenocarcinoma.

The mean age of TB patients $(38.67 \pm 18.8$ years) was significantly lower than that of the non-tuberculosis pleural effusion group $(67.00 \pm 13.79$ years) $(p=0.0001)$. No significant difference was found between the two groups in terms of gender $(p>0.05)$.

In the tuberculosis pleurisy group and control group, the mean D-Dimer values of pleural fluid were found to be $5.40 \pm 0.5 \mu \mathrm{g} / \mathrm{mL}$ to $5.37 \pm 0.95 \mu / \mathrm{mL}$, the mean $\mathrm{t}-\mathrm{PA}$ values of pleural fluid were $0.37 \pm 0.3$ $\mathrm{ng} / \mathrm{mL}$ to $0.34 \pm 0.09 \mathrm{ng} / \mathrm{mL}$, and the mean t-PA/PAl- 1 complex values of pleural fluid were $1.38 \pm 2.4$ to $0.99 \pm 0.71$. Upon statistical comparison of these three parameters, no significant difference was observed between the two groups ( $p>0.05$ ) (Table 2).

The mean fibrinogen value was significantly higher in the tuberculosis pleurisy group $(0.78 \pm 1.1 \mu \mathrm{g} / \mathrm{mL})$ than in the control group $(0.17 \pm 0.19$ $\mu \mathrm{g} / \mathrm{mL})(\mathrm{p}=0.049)$. In the same way, the mean PAI-1 value of pleural fluid was found to be significantly higher in the TP group $(30.81 \pm 40.7 \mathrm{ng} /$ $\mathrm{mL})$ compared to the control group $(12.53 \pm 37.32 \mathrm{ng} / \mathrm{mL})(\mathrm{p}=0.0001)$. The value of ADA was higher in the TP group than in the control group $(61.88 \pm 29.2 \mathrm{U} / \mathrm{L}$ and $39.43 \pm 27.80 \mathrm{U} / \mathrm{L}$, respectively) $(p=0.020)$. The concentrations in plasma fluid were as follows: for the mean D-Dimer, $8.37 \pm 27.6 \mathrm{ng} / \mathrm{mL}$ in the TP group and $1.75 \pm 1.10 \mathrm{ng} / \mathrm{mL}$ in the control group; for the mean PAl- 1 this was $8.37 \pm 27.6 \mathrm{ng} / \mathrm{mL}$ in the TP group and $1.75 \pm 1.10 \mathrm{ng} / \mathrm{mL}$ in the control group; for mean $\mathrm{t}-\mathrm{PA}$, this was $0.28 \pm 0.4$ $\mathrm{ng} / \mathrm{mL}$ in the TP group and $0.20 \pm 0.11 \mathrm{ng} / \mathrm{mL}$ in the control group; and for mean fibrinogen, these were $5.64 \pm 4.3 \mu \mathrm{g} / \mathrm{mL}$ in the TP group and $5.26 \pm 2.95 \mu \mathrm{g} / \mathrm{mL}$ in the control group. Considering these values, no statistically significant difference was found between the two groups ( $p>0.05)$. The tPA/PAI-1 value of plasma fluid in the TP group (1.04 \pm 2.6$)$ was significantly lower than in the control group $(1.13 \pm 0.99)(p=0.014)$ (Table 3). The area under the curve for PAI-1 (0.867), ADA (0.729), and fibrinogen (0.686) was above 0.5 and it was at the level of significance $(p<0.05)$ that could be used for the diagnosis of tuberculosis. The area under the curve for tPA/PAI-1 (0.464), tPA (0.426), and D-Dimer (0.352) was below 0.5 and it was not at the level of significance that could be used for the diagnosis of tuberculosis. PAI-1 was estimated to be the parameter that could be considered a priority for diagnosis. ADA and fibrinogen followed this (Table 4). No correlation was observed between ADA and fibrinogen and between ADA and PAI-1.

Table 1. Distribution of age and gender in cases with tuberculosis pleurisy and non-tuberculosis pleurisy

\begin{tabular}{|l|c|c|c|c|}
\hline & & $\begin{array}{c}\text { Tuberculosis } \\
\text { Pleurisy } \\
\text { Mean } \pm \text { SD }\end{array}$ & $\begin{array}{c}\text { Non-tuberculosis } \\
\text { Pleural Effusions } \\
\text { Mean } \pm \text { SD }\end{array}$ & P \\
\hline Age (Mean \pm SD) & Female (n, \%) & $38.67 \pm 18.8$ & $67.00 \pm 13.79$ & 0.0001 \\
& Male (n, \%) & $1033.3 \%$ & $428.6 \%$ & 0.752 \\
\hline
\end{tabular}


Table 2. In the cases with tuberculosis pleurisy and non-tuberculosis pleurisy, the mean values of parameters evaluated in pleural fluid

\begin{tabular}{|l|c|c|c|c|}
\hline & & $\begin{array}{c}\text { Tuberculosis } \\
\text { Pleurisy } \\
\text { Mean } \pm \text { SD }\end{array}$ & $\begin{array}{c}\text { Non-tuberculosis } \\
\text { Pleural Effusions } \\
\text { Mean } \pm \text { SD }\end{array}$ & P \\
& t-PA/PAl-1 & $1.38 \pm 2.4$ & $0.99 \pm 0.71$ & 0.705 \\
Pleural Fluid & t-PA/PAl-1 & $1.38 \pm 2.4$ & $0.99 \pm 0.71$ & 0.705 \\
& t-PA & $0.37 \pm 0.3$ & $0.34 \pm 0.09$ & 0.434 \\
& D-Dimer & $5.40 \pm 0.5$ & $5.37 \pm 0.95$ & 0.118 \\
\hline ADA: adenosine deaminase; PAl-1: plasminogen activator inhibitor -1; t-PA: tissue plasminogen activator & $61.88 \pm 29.2$ & $39.43 \pm 27.80$ & 0.020 \\
\hline
\end{tabular}

Table 3. In the cases with tuberculosis pleurisy and non-tuberculosis pleurisy, the mean values of parameters evaluated in plasma fluid

\begin{tabular}{|l|c|c|c|c|}
\hline & & $\begin{array}{c}\text { Tuberculosis } \\
\text { Pleurisy } \\
\text { Mean } \pm \text { SD }\end{array}$ & $\begin{array}{c}\text { Non-tuberculosis } \\
\text { Pleural Effusions } \\
\text { Mean } \pm \text { SD }\end{array}$ & P \\
\hline \multirow{3}{*}{ Plasma } & t-PA/PAl-1 & $1.04 \pm 2.6$ & $1.13 \pm 0.99$ & 0.014 \\
& t-PA/PAl-1 & $1.04 \pm 2.6$ & $1.13 \pm 0.99$ & 0.014 \\
& t-PA & $0.28 \pm 2.4$ & $0.20 \pm 0.11$ & 0.960 \\
\hline PAl-1: plasminogen activator inhibitor 1; t-PA: tissue plasminogen activator & $2,26 \pm 1,8$ & $2,34 \pm 1,98$ & 0,959 \\
\hline
\end{tabular}

Table 4. Significance levels of parameters that can be used for the diagnosis of tuberculosis pleurisy

\begin{tabular}{|c|c|c|c|c|}
\hline & \multirow{2}{*}{$\begin{array}{c}\text { Standard Area Under } \\
\text { Curve } \pm \text { Error }\end{array}$} & \multicolumn{2}{|c|}{ 95\% Confidence Interval } & \multirow[b]{2}{*}{$p$} \\
\hline & & Lower limit & Upper Limit & \\
\hline PAl-1 Fluid & $0.867 \pm 0.071$ & 0.73 & 1.00 & 0.0001 \\
\hline ADA & $0.729 \pm 0.084$ & 0.56 & 0.89 & 0.016 \\
\hline Fibrinogen & $0.686 \pm 0.083$ & 0.52 & 0.85 & 0.049 \\
\hline t-PA/PAI-1 & $0.464 \pm 0.101$ & 0.27 & 0.66 & 0.705 \\
\hline $\mathrm{t}-\mathrm{PA}$ & $0.426 \pm 0.090$ & 0.25 & 0.60 & 0.435 \\
\hline D-Dimer & $0.352 \pm 0.099$ & 0.16 & 0.55 & 0.118 \\
\hline
\end{tabular}

\section{DISCUSSION}

Tuberculosis pleurisies are exudates and the dominant cell group observed in the smear is the lymphocytes. Therefore, a differential diagnosis is needed with other exudative fluids, especially with malignant pleural fluids. In our study, it was revealed that PAI-1, ADA and fibrinogen could be used in pleural fluid for the differential diagnosis of TP and that these parameters contribute to the diagnosis.

The diagnostic value of pleural biopsy, the most commonly used method for diagnosis, ranges from $50 \%$ to $80 \%$ during the first implementation. The contribution of the second biopsy before diagnosis is between $10 \%$ and $40 \%(8,9)$. Demonstrations of basil cells in pleural fluid or granuloma in pleural biopsy are two valuable diagnostic methods for final diagnosis. However, the diagnostic pos- sibility of fluid in TP through smears and/or cultures is low (50\%). In tuberculosis pleurisy, due to the presence of undiagnosed cases in the rate of $20-30 \%$ in spite of microbiological examination of pleural fluid (smear and culture) and pleural biopsy, many researchers investigated some markers providing rapid diagnosis and not requiring invasive procedures as alternative methods in pleural fluid and blood.

The amount of fibrin occurring when pleura is exposed to inflammation for any reason is a result of the balance between fibrinogenesis and fibrinolysis. Fibrinogenesis appears when factors on behalf of fibrinogenesis such as TNF- $\alpha$, TGF- $\beta$ and PAI-1 are dominant; as the amount of fibrin increases, fibrinolysis occurs. Three important enzyme systems play a role in the regulation of hemostasis in the fibrinolytic system. Of these enzyme systems, the first one involves plasminogen 
activators, the second involves plasminogen activator inhibitors and the third involves thrombin-activable fibrinolysis inhibitor (TAFI). Fibrinogen is a glycoprotein synthesised in the liver and is found in high concentrations during acute periods of inflammatory events such as tuberculosis and pneumonia. With this consideration, its place in the differential diagnosis of pleural fluids was investigated. It was detected at lower concentrations in pleural fluid compared to the serum $(10,11)$. On the other hand, increased fibrinogen degradation products were found in malignant pleural fluids, parapneumonic pleurisies and pulmonary embolism-associated pleural fluids.

The availability of a test offering simple and precise results for tuberculosis pleurisy will provide great advantages. Therefore, we aimed to investigate the contribution of fibrinolytic system parameters to diagnosis considering hypercoagulation increase in TP.

In our study, the mean level of D-Dimer was found to be high in TP. However, no significant difference was observed between the groups. Özkara et al. (12) found the levels of pleural fluid and plasma D-Dimer to be significantly higher in TP cases than in non-tuberculosis pleurisy cases. They also reported a positive correlation between the D-Dimer level of pleural fluid and the radiological extent of pleural effusion in TP. In their study, Lu et al. (13) revealed that D-Dimer levels of pleural fluid were higher in patients with TP and empyema than in those with malignant pleural effusion and that the D-Dimer level of pleural fluid correlated with LDH of pleural fluid. Ataç et al. (14) found that plasma D-Dimer level increased significantly in patients with pulmonary tuberculosis compared to healthy individuals, but did not differ from the increased level of D-Dimer in non-tuberculosis lung diseases. In our study, the fact that no significant difference was found between the two groups was attributed to the low number of the patients. There was no significant difference between t-PA and t-PA/PAI-1 complex values in the TP and control groups. Fibrinogen and PAI-1 values were higher in the TP group than in the control group and no statistically significant difference was detected between groups. In the study of Aleman et al. (15), the levels of fibrinolytic system parameters were found to be higher in exudative fluids than in transudative fluids. PAI-1 level was prominently higher in TP, empyema and parapneumonic effusion of exudative fluids than in malignant effusion. In our study, the value of PAl-1 was also found to be higher in exudative fluids. In our study, the absence of a significant difference for t-PA value was attributed to the low number of cases included. Hua et al. (16) compared the levels of proinflammatory cytokines and fibrinolytic enzyme in patients with TP and malignant pleural fluid and found that the levels in pleural fluid were higher than those in blood for both groups. In this study, TNF-a and PAI-1 levels were found to be higher in TP and t-PA level was higher in malignant pleural fluid. In TP, there was a positive correlation between PAI-1 values and the PAI-1/t-PA ratio, and a negative correlation between $t-P A$ values and TNF- $\alpha$ and IL-1 $\beta$. In malignant fluid, a positive correlation was reported between PAI- 1 values and TNF- $a$ and IL-1 $\beta$. In our study, no significant difference was found between the TP group and the control group in terms of t-PA values. This outcome might have resulted from the coexistence of malignant pleural fluid and transudative pleural fluid in the control group as well as the low number of patients included. Phlip-Joet et al. (17) found higher PAI-1 levels in TP and empyema compared to malignant pleural fluid associated with heart failure. In the same study, a correlation was found between PAI-1 level and pleural fluid neutrophil count and plasma fibrinogen levels. The highest t-PA and u-PA levels of pleural fluid were observed in patients with cancer, especially with lymphoma. Türken et al. (18) revealed the values of plasma fibrinogen, factor VIII and PAI-1 to be increased and the values of antithrombin III and Protein $C$ to be decreased in active pulmonary tuberculosis. In our study, these parameters presented a significant difference in pleural fluid, not in plasma.

With regard to the points that may be criticised in our study, the mean ages of the patients with malignant pleural fluid and transudative fluid in the TP and control groups were not similar. Moreover, we had to restrict the number of cases to 44 because we studied two separate materials for each case (pleura and plasma) and the number of kits that we had was limited. In particular, the low number of cases in the control group was one of the main limitations of our study.

\section{CONCLUSION}

The findings obtained in our study suggest that fibrinogenesis increases in pleura both systemically and locally in TP and the fibrinolytic system activates as a response to this condition. This explains the presence of fibrinous pleuritis in pleural biopsy samples in many cases with TP. For the cases not diagnosed using conventional methods, the examination of fibrinolytic system parameters may contribute to the process of diagnosing. However, further studies should be conducted with a larger number of cases and more appropriate patient groups.

\section{Ethics Committee Approval: N/A.}

Informed Consent: Written informed consent was obtained from patients who participated in this study.

Peer-review: Externally peer-reviewed.

Author Contributions: Concept - B.A., F.K.; Design - B.A., F.K.; Supervision - F.K.; Resource - F.K., B.A.; Materials - S.Y., B.A.; Data Collection\&/or Processing - H.U., B.A.; Analysis\&/or Interpretation - B.A., F.K.; Literature Search - B.Y., B.A.; Writing - B.A.; Critical Reviews - F.K., S.Y.

Conflict of Interest: No conflict of interest was declared by the authors.

Financial Disclosure: The authors declared that this study has received no financial support.

\section{REFERENCES}

1. Pérez-Rodriguez E, Castro DJ, Light RW. Effusions from tuberculosis. In: (Ed) Light RW, Lee YCG Textbook of Pleural Diseases. Arnold Medical Pres Great Britain. 2003. p.329-344.

2. Schlossberg D. Tuberculosis. Second Edit. Springer-verlag. New York Inc $1988 ; 67$.

3. Yoon HJ, Song YG, Park WI, Choi JP, Chang KH, Kim JM. Clinical manifestations and diagnosis of extrapulmonary tuberculosis. Yonsei Med J 2004; 45: 453-61.

4. Light RW. Thoracentesis and pleural biopsy. In: Wang KP (ed). Biopsy techniques in pulmonary disorders. New York Raven Pres 1989; 29-44.

5. Mathur PN, Astoul P, Boutin C. Medical thoracoscopy. Technical details. Clin Chest Med 1995; 16: 479-86.

6. Roth BJ. Searching for tuberculosis in the pleural space. Chest 1999; 116: 3-5.

7. Light RW, Mac Gregor MI, Luchsinger PC, Ball WC Jr. Pleural effusion: the diagnostic separation of transudates and exudates. Ann Intern Med 1972;77:507-13.

8. Mestitz P, Purves MJ, Pollard AC. Pleural biopsy in the diagnosis of pleural effusion. Lancet 1958; 2: 1349-53.

9. Poppius $\mathrm{H}$, Kokkola K. Diagnosis and differantial diagnosis in tuberculous pleurisy. Scand J Respir Dis 1968; 63: 105-10. 
10. Widstrom O, Kockum C, Nilsson BS. Fibrinogen, fibrin(ogen)degredation products and fibrinopeptide $A$ in pleural effusions. Scand J Respir Dis 1978; 59:210-5.

11. Alpar S, Eryılmaz T, Mutlu AG. Diagnostic value of fibrinogen in pleural fluid. Respiratory Diseases 1999; 10: 163-6.

12. Özkara B, Tozkoparan E, Uçar E, Gümüş S, Çakır E, Akgül EÖ, et al. Tuberculous pleurisy and plasma D-dimer levels: diagnostic value and association with clinical parameters. J Clin Anal Med 2010; 1: 6-12.

13. Lu YD, Chen $P, X u M$. Detection of D-Dimer in pleural effusion. Hunan yıKe Xue Xue Bao 2000; 28: 71-2.

14. Ataç G, Güngör G, Aksoy E, Takır H, Bölükbaşı Y, Can G. Plasma d-dimer levels in cases with active pulmonary tuberculosis. Turk Thorac J 2005; 6: 57-61.
15. Alemán C, Alegre J, Monasterio J, Segura RM, Armadans L, Anglés A, et al. Association between inflammatory mediators and the fibrinolysis system in infectious pleural effusions. Clinical Science 2003; 105: 601-7.

16. Hua CC, Chang LC, Chen YC, Chang SC. Pro inflammatory cytokines and fibrinolytic enzymes in tuberculous and malignant pleural effusions. Chest 1999; 116: 1292-6.

17. Philip-Joët F, Alessi MC, Philip-Joët C, Aillaud M, Barriere JR, Arnaud A, et al. Fibrinolytic and inflammatory processes in pleural effusions. Eur Respir J 1995; 8:1352-6.

18. Turken O, Kunter E, Sezer M, Solmazgul E, Cerrahoglu K, Bozkanat E, et al Hemostatic changes in active pulmonary tuberculosis. Int J Tuberc Lung Dis $2002 ; 6: 927-32$ 